\title{
METODE FUZZY ANALYTICAL HIERARCHY PROCESS UNTUK PEMILIHAN NOTEBOOK BERBASIS ANDROID
}

\author{
Akik Hidayat \\ Prodi Teknik Informatika, Fakultas MIPA, Universitas Padjadjaran \\ Jl. Raya Bandung Sumedang KM 21 Jatinangor Sumedang 45363 \\ akik@unpad.ac.id \\ Ebby Syabilal Rasyad \\ Prodi Matematika, Fakultas MIPA, Universitas Padjadjaran \\ Jl. Raya Bandung Sumedang KM 21 Jatinangor Sumedang 45363 \\ syabilalrasyad@gmail.com
}

\begin{abstract}
Nowadays, there are many brands of notebook with various specifications and prices are available in markets. This condition makes consumers face difficulties in determining the appropriate option according to their needs and budget. Correspondingly, development of computer has also increased, for instance the use of computer in giving the best decision about a certain issue, in this case it is a matter of choosing a notebook. Therefore, it is important to develop a decision support system in order to choose notebooks by using Fuzzy Analytical Hierarchy Process (FAHP) so that consumers can determine the fittest notebook in accordance with the consumer's wishes and budget.
\end{abstract}

Keywords: Fuzzy Analytical Hierarchy Process, notebook selection, decision support systems.

\begin{abstract}
ABSTRAK. Dewasa ini banyak merk notebook dengan beragam spesifikasi dan harga yang dijual dipasaran membuat konsumen menjadi kesulitan dalam menentukan pilihan yang sesuai dengan keinginan dan anggaran yang mereka miliki. Sejalan dengan itu, perkembangan penggunaan komputer juga meningkat, salah satunya adalah penggunaan komputer dalam memberikan keputusan terbaik pada suatu masalah, dalam hal ini adalah masalah pemilihan notebook. Oleh karena itu, maka dalam hal ini telah dikembangkan perancangan sebuah system pendukung keputusan pemilihan notebook dengan menggunakan metode Fuzzy Analytical Hierarchy Process (FAHP), dengan tujuan konsumen dapat menentukan pilihan laptop dengan tepat sesuai dengan keinginan dan anggaran yang dimilikinya.
\end{abstract}

Kata kunci: Fuzzy Analytical Hierarchy Process, pemilihan notebook, sistem pendukung keputusan.

\section{PENDAHULUAN}

Seiring pesatnya perkembangan teknologi, handphone yang dulu digunakan hanya untuk SMS (Short Message Service) dan telepon, kini handphone hadir dengan fitur-fitur tambahan yang membuatnya kini dikenal 
dengan sebutan smartphone. Fitur tambahan tersebut sangat mendukung segala aktifitas penggunanya seperti camera, games, internet browser, email, GPS (Global Positioning System), dan masih banyak lagi fitur lainnya. Android yang kini sangat dikenal dalam lingkup smartphone merupakan suatu Operating System (OS) yang berbasis Linux yang menjadi platform-nya. Android dengan sifatnya yang open source membuat pengembang leluasa untuk menciptakan aplikasi mereka yang berbasis Android, salah satunya aplikasi pemilihan notebook.

Untuk mempertimbangkan beberapa faktor yang berkaitan dengan pemilihan notebook tersebut, dibutuhkan suatu sistem pendukung keputusan yang dapat mempercepat dan mempermudah pengguna. Fuzzy Analytical Hierarchy Process (FAHP) adalah suatu sistem pendukung keputusan yang merupakan gabungan antara metode AHP dengan pendekatan konsep fuzzy. Sedangkan Tujuan adalah untuk menerapkan metode FAHP dalam pemilihan notebook, Membangun aplikasi pemilihan notebook menggunakan metode FAHP sehingga Mempermudah pembeli untuk memilih notebook sesuai kriteria yang diinginkan.

\section{HASIL DAN PEMBAHASAN}

\subsection{Metode Penelitian}

Metode yang digunakan dalam penelitian ini adalah Melakukan studi literatur dan merancang program menggunakan Java Android.

\subsection{Fuzzy Analytical Hierarchy Process (FAHP)}

Metode FAHP memecahkan masalah pemilihan yang menggunakan konsep teori himpunan fuzzy dan analisis struktur hirarkis. Pada dasarnya, metode FAHP merupakan perluasan dari metode AHP biasa yang menggunakan perhitungan bilangan real, menjadi metode FAHP yang melakukan perhitungan menggunakan bilangan fuzzy.

Karena pada dasarnya AHP tidak mengikutsertakan ketidakjelasan pertimbangan personal, maka AHP telah diperbaiki dengan memanfaatkan pendekatan logika fuzzy. Pada FAHP, alternatif kriteria dari perbandingan berpasangan ditunjukan dengan variabel linguistik. 
Fuzzy Analytical Hierarchy Process (FAHP) memasukkan nilai fuzzy pada Analytic Hierarchy Process (AHP) yang telah dikembangkan oleh Thomas L. Saaty.

Dalam pendekatan FAHP digunakan Triangular Fuzzy Number (TFN) untuk proses fuzzyfikasi dari matriks perbandingan yang bersifat crisp. Data yang kabur akan dipresentasikan dalam TFN. Setiap fungsi keanggotaan didefinisikan dalam 3 parameter yakni, $l, m$, dan $u$, dimana $l$ adalah nilai kemungkinan terendah, $m$ adalah nilai kemungkinan tengah dan $u$ adalah nilai kemungkinan teratas pada interval putusan pengambil keputusan. Nilai $l, m$, dan $u$ dapat juga ditentukan oleh pengambil keputusan itu sendiri. Tulisan ini mengajukan tiga parameter bilangan fuzzy untuk merepresentasikan skala Saaty (1-9) sesuai dengan tingkat kepentingannya, yakni (Alias, Hashim, \& Samsudin, 2009):

$$
\begin{gathered}
\tilde{1} \equiv(1,1,1) \\
\tilde{x} \equiv(x-1, x, x+1) ; \forall x=2,3, \ldots, 8 \\
\tilde{9} \equiv(9,9,9)
\end{gathered}
$$

Triangular Fuzzy Number (TFN) dapat menunjukkan kesubjektifan perbandingan berpasangan atau dapat menunjukkan derajat yang pasti dari kekaburan (ketidakpastian). Dalam hal ini variabel linguistik dapat digunakan oleh pengambil keputusan untuk merepresentasikan kekaburan data seandainya ada ketidaknyamanan dengan TFN. TFN dan variabel linguistiknya sesuai dengan skala Saaty ditunjukkan pada tabel berikut (Alias, Hashim, \& Samsudin, 2009):

Tabel 1. Tabel Fungsi Keanggotaan Fuzzy

\begin{tabular}{|c|c|c|}
\hline Definisi & Skala Saaty & TFN \\
\hline $\begin{array}{c}\text { Equally Important (sama penting) } \\
\text { poderately more important (sedikit lebih } \\
\text { penting) }\end{array}$ & 1 & $(1,1,1)$ \\
\hline $\begin{array}{r}\text { Strongly More Important (lebih penting) } \\
\text { penting) }\end{array}$ & 5 & $(4,3,4)$ \\
\hline $\begin{array}{r}\text { Very strongly more important (sangat } \\
\text { penting) }\end{array}$ & 7 & $(6,7,8)$ \\
\hline $\begin{array}{c}\text { Extremely more important (mutlak lebih } \\
\text { Intermediate Values (nilai yang berdekatan) }\end{array}$ & 9 & $(9,9,9)$ \\
\hline
\end{tabular}


Untuk melakukan prioritas lokal dari matriks fuzzy pairwise comparison sudah banyak metode yang dikembangkan oleh para ahli sebelumnya. Dengan mengkombinasikan prosedur AHP dengan operasi aritmetik untuk bilangan fuzzy, prioritas lokal dapat diperoleh dengan menggunakan persamaan berikut (Febryansyah, 2006):

$$
S_{i}=\sum_{j=i}^{m} M_{g_{i}}^{j} \otimes\left[\sum_{i=1}^{n} \sum_{j=1}^{m} M_{g_{i}}^{j}\right]^{-1}
$$

dengan: $\quad S_{i}=$ fuzzy synthetic extent

$$
\begin{aligned}
& \text { gi } i=\text { goal set }(i=1,2,3, \ldots, n) \\
& M_{g_{i}}^{j}=\text { Triangular Fuzzy Number }(j=1,2,3, \ldots, m) \\
& \sum_{j=i}^{m} M_{g_{i}}^{j}=\left(\sum_{j=1}^{m} l_{j} ; \sum_{j=1}^{m} m_{j} ; \sum_{j=1}^{m} u_{j}\right)
\end{aligned}
$$

dan

$$
\left[\sum_{i=1}^{n} \sum_{j=1}^{m} M_{g_{i}}^{j}\right]^{-1}=\left(\sum_{j=1}^{m} l_{j} ; \sum_{j=1}^{m} m_{j} ; \sum_{j=1}^{m} u_{j}\right)^{-1} .
$$

Karena $l<m<u$, persamaan (4) menjadi:

$$
\left[\sum_{i=1}^{n} \sum_{j=1}^{m} M_{g_{i}}^{j}\right]^{-1}=\left(\frac{1}{\sum_{i=1}^{n} u_{i}} ; \frac{1}{\sum_{i=1}^{n} m_{i}} ; \frac{1}{\sum_{i=1}^{n} l_{i}}\right),
$$

sehingga persamaan (2) menjadi

$$
S_{i}=\left(\sum_{j=1}^{m} l_{j} ; \sum_{j=1}^{m} m_{j} ; \sum_{j=1}^{m} u_{j}\right) \otimes\left(\frac{1}{\sum_{i=1}^{n} u_{i}} ; \frac{1}{\sum_{i=1}^{n} m_{i}} ; \frac{1}{\sum_{i=1}^{n} l_{i}}\right)
$$

dengan: $\quad l=$ nilai batas bawah (kemungkinan terendah),

$m=$ nilai yang paling menjanjikan (kemungkinan tengah),

$u=$ nilai batas atas (kemungkinan teratas).

Untuk menentukan nilai perbandingan berpasangan dari $S_{i}$ digunakan rumus:

$$
V\left(S_{i} \geq S_{k}\right)=\left\{\begin{array}{lr}
1 ; & m_{S_{i}} \geq m_{S_{k}} \\
0 ; & l_{S_{k}} \geq u_{S_{i}} \\
\frac{\left(l_{S_{k}}-u_{S_{i}}\right)}{\left(\left(m_{S_{i}}-u_{S_{i}}\right)-\left(m_{S_{k}}-l_{S_{k}}\right)\right)} ; & \text { lainnya }
\end{array}\right.
$$

dengan: $\quad V\left(S_{i} \geq S_{k}\right)=$ nilai perbandingan antara fuzzy synthetic extent,

$$
\begin{aligned}
& S_{i}=\text { nilai fuzzy synthetic extent kriteria } i, \\
& S_{k}=\text { nilai fuzzy synthetic extent kriteria } k, \\
& d^{\prime}{ }_{i}=\min \left(V\left(S_{i} \geq S_{k}\right)\right) ; \text { untuk } k=1,2,3, \ldots, n ; k \neq i, \\
& W^{\prime}=\left(d^{\prime}{ }_{i}, d^{\prime}{ }_{i+1}, d^{\prime}{ }_{i+2}, \ldots, d^{\prime}{ }_{i+n-1}\right)^{T},
\end{aligned}
$$




$$
\begin{aligned}
& d_{i}=\frac{d_{\prime}^{\prime}}{\sum_{i=1}^{n} d_{i}}, \\
& W=\left(d_{i}, d_{i+1}, d_{i+2}, \ldots, d_{i+n-1}\right)^{T},
\end{aligned}
$$

dengan: $\quad d^{\prime}{ }_{i}=$ bobot kriteria $I$,

$W^{\prime}=$ vektor bobot kriteria,

$d_{i}=$ normalisasi bobot

$W=$ normalisasi vektor bobot kriteria,

$n=$ jumlah kriteria.

Operasi aritmetika untuk bilangan fuzzy dapat dilihat dari persamaan berikut:

1. $\tilde{n}_{1} \oplus \tilde{n}_{2}=\left(\tilde{n}_{1 l}+\tilde{n}_{2 l} ; \tilde{n}_{1 m}+\tilde{n}_{2 m} ; \tilde{n}_{1 u}+\tilde{n}_{2 u}\right)$

2. $\tilde{n}_{1} \otimes \tilde{n}_{2}=\left(\tilde{n}_{1 l} \times \tilde{n}_{2 l} ; \tilde{n}_{1 m} \times \tilde{n}_{2 m} ; \tilde{n}_{1 u} \times \tilde{n}_{2 u}\right)$

3. $1 / \tilde{n}_{1}=\left(1 / \tilde{n}_{1 u} ; 1 / \tilde{n}_{1 m} ; 1 / \tilde{n}_{1 l}\right)$

Sedangkan prioritas global diperoleh dengan mengalikan normalisasi skala setiap kriteria wj dengan normalisasi bobot $d\left(A_{i}\right)$ dan menjumlahkan semua hasil perkalian dari setiap kriteria. Persamaan dapat dituliskan sebagai berikut:

$$
\tilde{P}_{i}=\left(\widetilde{w}_{1} \otimes d\left(A_{1}\right)\right) \oplus\left(\widetilde{w}_{2} \otimes d\left(A_{2}\right)\right) \oplus \cdots \oplus\left(\widetilde{w}_{j} \otimes d\left(A_{i}\right)\right)
$$

\subsection{Contoh Kasus dan Perhitungan}

Pada contoh kasus ini akan diinputkan skala prioritas pada setiap kriteria yang ada sebagai berikut: jumlah inti 2, kecepatan processor 6, RAM 3, lebar layar 7, kapasitas SSD 1, kapasitas HDD 4, harga 9.

Tabel 2. Input Kriteria oleh User

\begin{tabular}{|l|c|c|}
\hline \multicolumn{3}{|c|}{ INPUT } \\
\hline Jumlah Inti & C1 & 2 \\
\hline Kecepatan Processor & C2 & 6 \\
\hline RAM & C3 & 3 \\
\hline Lebar Layar & C4 & 7 \\
\hline Kapasitas SSD & C5 & 1 \\
\hline Kapasitas HDD & C6 & 4 \\
\hline Harga & C7 & 9 \\
\hline
\end{tabular}


Setelah ditentukan skala prioritas, kemudian akan dilakukan perhitungan sebagai berikut:

1. Menghitung matriks perbandingan berpasangan

Tabel 3. Rumus Umum Matriks Perbandingan Berpasangan

\begin{tabular}{|c|c|c|c|c|c|c|c|}
\hline \multicolumn{7}{|c|}{ Matriks Perbandingan Berpasangan } \\
\hline & $\mathrm{C} 1$ & $\mathrm{C} 2$ & $\mathrm{C} 3$ & $\mathrm{C} 4$ & $\mathrm{C} 5$ & $\mathrm{C} 6$ & $\mathrm{C} 7$ \\
\hline $\mathrm{C} 1$ & $\mathrm{C} 1 / \mathrm{C} 1$ & $\mathrm{C} 1 / \mathrm{C} 2$ & $\mathrm{C} 1 / \mathrm{C} 3$ & $\mathrm{C} 1 / \mathrm{C} 4$ & $\mathrm{C} 1 / \mathrm{C} 5$ & $\mathrm{C} 1 / \mathrm{C} 6$ & $\mathrm{C} 1 / \mathrm{C} 7$ \\
\hline $\mathrm{C} 2$ & $\mathrm{C} 2 / \mathrm{C} 1$ & $\mathrm{C} 2 / \mathrm{C} 2$ & $\mathrm{C} 2 / \mathrm{C} 3$ & $\mathrm{C} 2 / \mathrm{C} 4$ & $\mathrm{C} 2 / \mathrm{C} 5$ & $\mathrm{C} 2 / \mathrm{C} 6$ & $\mathrm{C} 2 / \mathrm{C} 7$ \\
\hline $\mathrm{C} 3$ & $\mathrm{C} 3 / \mathrm{C} 1$ & $\mathrm{C} 3 / \mathrm{C} 2$ & $\mathrm{C} 3 / \mathrm{C} 3$ & $\mathrm{C} 3 / \mathrm{C} 4$ & $\mathrm{C} 3 / \mathrm{C} 5$ & $\mathrm{C} 3 / \mathrm{C} 6$ & $\mathrm{C} 3 / \mathrm{C} 7$ \\
\hline $\mathrm{C} 4$ & $\mathrm{C} 4 / \mathrm{C} 1$ & $\mathrm{C} 4 / \mathrm{C} 2$ & $\mathrm{C} 4 / \mathrm{C} 3$ & $\mathrm{C} 4 / \mathrm{C} 4$ & $\mathrm{C} 4 / \mathrm{C} 5$ & $\mathrm{C} 4 / \mathrm{C} 6$ & $\mathrm{C} 4 / \mathrm{C} 7$ \\
\hline $\mathrm{C} 5$ & $\mathrm{C} 5 / \mathrm{C} 1$ & $\mathrm{C} 5 / \mathrm{C} 2$ & $\mathrm{C} 5 / \mathrm{C} 3$ & $\mathrm{C} 5 / \mathrm{C} 4$ & $\mathrm{C} 5 / \mathrm{C} 5$ & $\mathrm{C} 5 / \mathrm{C} 6$ & $\mathrm{C} 5 / \mathrm{C} 7$ \\
\hline $\mathrm{C} 6$ & $\mathrm{C} 6 / \mathrm{C} 1$ & $\mathrm{C} 6 / \mathrm{C} 2$ & $\mathrm{C} 6 / \mathrm{C} 3$ & $\mathrm{C} 6 / \mathrm{C} 4$ & $\mathrm{C} 6 / \mathrm{C} 5$ & $\mathrm{C} 6 / \mathrm{C} 6$ & $\mathrm{C} 6 / \mathrm{C} 7$ \\
\hline $\mathrm{C} 7$ & $\mathrm{C} 7 / \mathrm{C} 1$ & $\mathrm{C} 7 / \mathrm{C} 2$ & $\mathrm{C} 7 / \mathrm{C} 3$ & $\mathrm{C} 7 / \mathrm{C} 4$ & $\mathrm{C} 7 / \mathrm{C} 5$ & $\mathrm{C} 7 / \mathrm{C} 6$ & $\mathrm{C} 7 / \mathrm{C} 7$ \\
\hline
\end{tabular}

Tabel 4. Hasil Perhitungan Matriks Perbandingan Berpasangan

\begin{tabular}{|c|c|c|c|c|c|c|c|}
\hline \multicolumn{7}{|c|}{ Matriks Perbandingan Berpasangan } \\
\hline & C1 & C2 & C3 & C4 & C5 & C6 & C7 \\
\hline C1 & 1.0000 & 0.3333 & 0.6667 & 0.2857 & 2.0000 & 0.5000 & 0.2222 \\
\hline C2 & 3.0000 & 1.0000 & 2.0000 & 0.8571 & 6.0000 & 1.5000 & 0.6667 \\
\hline C3 & 1.5000 & 0.5000 & 1.0000 & 0.4286 & 3.0000 & 0.7500 & 0.3333 \\
\hline C4 & 3.5000 & 1.1667 & 2.3333 & 1.0000 & 7.0000 & 1.7500 & 0.7778 \\
\hline C5 & 0.5000 & 0.1667 & 0.3333 & 0.1429 & 1.0000 & 0.2500 & 0.1111 \\
\hline C6 & 2.0000 & 0.6667 & 1.3333 & 0.5714 & 4.0000 & 1.0000 & 0.4444 \\
\hline C7 & 4.5000 & 1.5000 & 3.0000 & 1.2857 & 9.0000 & 2.2500 & 1.0000 \\
\hline
\end{tabular}

2. Menghitung TFN dari matriks perbandingan berpasangan

Tabel 5. Rumus Umum TFN Matriks Perbandingan Berpasangan

\begin{tabular}{|c|c|c|c|c|c|c|c|c|c|c|c|c|}
\hline & & $\mathrm{C} 1$ & & & $\mathrm{C} 2$ & & & $\mathrm{C} 3$ & & & $\mathrm{C} 4$ & \\
\hline & $\mathrm{L}$ & $\mathrm{m}$ & $\mathrm{u}$ & 1 & $\mathrm{~m}$ & $\mathrm{U}$ & 1 & M & $\mathrm{u}$ & 1 & $\mathrm{~m}$ & $\mathrm{u}$ \\
\hline $\mathrm{C} 1$ & $\begin{array}{c}\mathrm{mC} 1- \\
1\end{array}$ & $\mathrm{C} 1 / \mathrm{C} 1$ & $\mathrm{mC} 1+1$ & $\mathrm{mC} 2-1$ & $\mathrm{C} 1 / \mathrm{C} 2$ & $\mathrm{mC} 2+1$ & $\mathrm{mC} 3-1$ & $\mathrm{C} 1 / \mathrm{C} 3$ & $\mathrm{mC} 3+1$ & $\mathrm{mC} 4-1$ & $\mathrm{C} 1 / \mathrm{C} 4$ & $\mathrm{mC} 4+1$ \\
\hline C2 & $\begin{array}{c}\mathrm{mC} 1- \\
1\end{array}$ & $\mathrm{C} 2 / \mathrm{C} 1$ & $\mathrm{mC} 1+1$ & $\mathrm{mC} 2-1$ & $\mathrm{C} 2 / \mathrm{C} 2$ & $\mathrm{mC} 2+1$ & $\mathrm{mC} 3-1$ & $\mathrm{C} 2 / \mathrm{C} 3$ & $\mathrm{mC} 3+1$ & $\mathrm{mC} 4-1$ & $\mathrm{C} 2 / \mathrm{C} 4$ & $\mathrm{mC} 4+1$ \\
\hline C3 & $\begin{array}{c}\mathrm{mC} 1- \\
1\end{array}$ & $\mathrm{C} 3 / \mathrm{C} 1$ & $\mathrm{mC} 1+1$ & $\mathrm{mC} 2-1$ & $\mathrm{C} 3 / \mathrm{C} 2$ & $\mathrm{mC} 2+1$ & mC3-1 & C3/C3 & $\mathrm{mC} 3+1$ & $\mathrm{mC} 4-1$ & $\mathrm{C} 3 / \mathrm{C} 4$ & $\mathrm{mC} 4+1$ \\
\hline C & $\begin{array}{c}\mathrm{mC} 1- \\
1\end{array}$ & $\mathrm{C} 4 / \mathrm{C} 1$ & $\mathrm{mC} 1+1$ & $\mathrm{mC} 2-1$ & $\mathrm{C} 4 / \mathrm{C} 2$ & $\mathrm{mC} 2+1$ & mC3-1 & $\mathrm{C} 4 / \mathrm{C} 3$ & $\mathrm{mC} 3+1$ & $\mathrm{mC} 4-1$ & $\mathrm{C} 4 / \mathrm{C} 4$ & $\mathrm{mC} 4+1$ \\
\hline
\end{tabular}




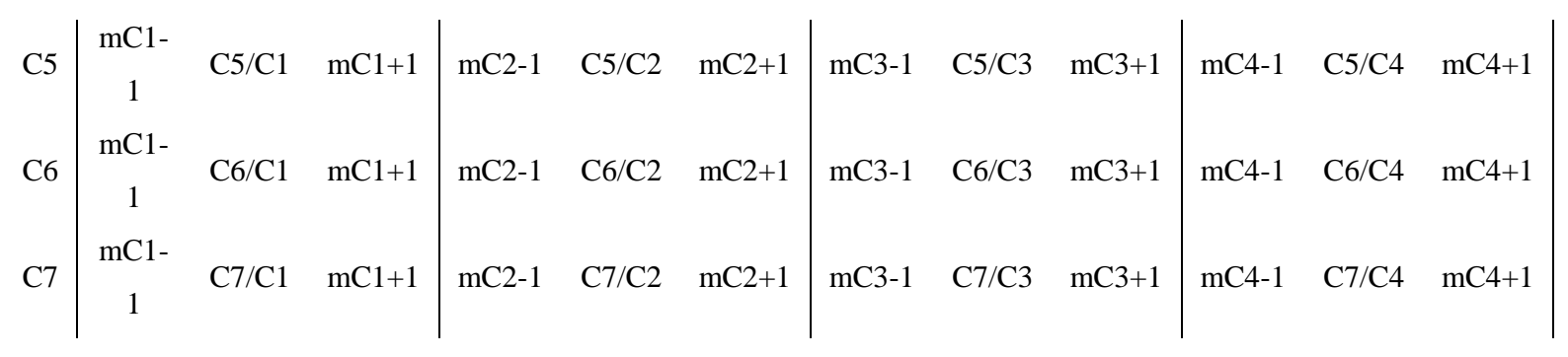

\begin{tabular}{|c|c|c|c|c|c|c|c|c|}
\hline & C5 & & & C6 & & & C7 & \\
\hline $\mathrm{L}$ & $\mathrm{m}$ & $\mathrm{u}$ & 1 & $\mathrm{~m}$ & $\mathrm{u}$ & 1 & $\mathrm{M}$ & $\mathrm{u}$ \\
\hline $\mathrm{mC} 5-1$ & $\mathrm{C} 1 / \mathrm{C} 5$ & $\mathrm{mC} 5+1$ & mC6-1 & $\mathrm{C} 1 / \mathrm{C} 6$ & $\mathrm{mC} 6+1$ & $\mathrm{mC} 7-1$ & $\mathrm{C} 1 / \mathrm{C} 7$ & $\mathrm{mC} 7+1$ \\
\hline mC5-1 & $\mathrm{C} 2 / \mathrm{C} 5$ & $\mathrm{mC} 5+1$ & mC6-1 & $\mathrm{C} 2 / \mathrm{C} 6$ & $\mathrm{mC} 6+1$ & $\mathrm{mC} 7-1$ & $\mathrm{C} 2 / \mathrm{C} 7$ & $\mathrm{mC} 7+1$ \\
\hline mC5-1 & $\mathrm{C} 3 / \mathrm{C} 5$ & $\mathrm{mC} 5+1$ & mC6-1 & $\mathrm{C} 3 / \mathrm{C} 6$ & $\mathrm{mC} 6+1$ & mC7-1 & $\mathrm{C} 3 / \mathrm{C} 7$ & $\mathrm{mC} 7+1$ \\
\hline mC5-1 & $\mathrm{C} 4 / \mathrm{C} 5$ & $\mathrm{mC} 5+1$ & mC6-1 & $\mathrm{C} 4 / \mathrm{C} 6$ & $\mathrm{mC} 6+1$ & mC7-1 & $\mathrm{C} 4 / \mathrm{C} 7$ & $\mathrm{mC} 7+1$ \\
\hline $\mathrm{mC5}-1$ & $\mathrm{C} 5 / \mathrm{C} 5$ & $\mathrm{mC} 5+1$ & $\mathrm{mC6}-1$ & C5/C6 & $\mathrm{mC6}+1$ & $\mathrm{mC} 7-1$ & $\mathrm{C} 5 / \mathrm{C} 7$ & $\mathrm{mC} 7+1$ \\
\hline $\mathrm{mC} 5-1$ & C6/C5 & $\mathrm{mC} 5+1$ & mC6-1 & C6/C6 & $\mathrm{mC} 6+1$ & $\mathrm{mC} 7-1$ & $\mathrm{C} 6 / \mathrm{C} 7$ & $\mathrm{mC} 7+1$ \\
\hline mC5-1 & $\mathrm{C} 7 / \mathrm{C} 5$ & $\mathrm{mC} 5+1$ & mC6-1 & $\mathrm{C} 7 / \mathrm{C} 6$ & $\mathrm{mC} 6+1$ & $\mathrm{mC7}-1$ & $\mathrm{C} 7 / \mathrm{C} 7$ & $\mathrm{mC} 7+1$ \\
\hline
\end{tabular}

Jika $\mathrm{m}=1$, maka $1=1$ dan $\mathrm{u}=1$; jika $\mathrm{m}=9$, maka $1=9$ dan $\mathrm{u}=9$; jika $1 \leq 0$, maka $1=m$; jika $u \geq 0$, maka $u=m$.

Tabel 6. Hasil Perhitungan TFN Matriks Perbandingan Berpasangan

\begin{tabular}{|c|c|c|c|c|c|c|c|c|c|c|c|c|c|}
\hline & & $\mathrm{C} 1$ & & & $\mathrm{C} 2$ & & & & $\mathrm{C} 3$ & & & $\mathrm{C} 4$ & \\
\hline & $\mathrm{L}$ & $\mathrm{m}$ & $\mathrm{u}$ & 1 & $\mathrm{~m}$ & $\mathrm{u}$ & & 1 & M & $\mathrm{u}$ & 1 & $\mathrm{~m}$ & $\mathrm{u}$ \\
\hline $\mathrm{C} 1$ & 1.0000 & 1.0000 & 1.0000 & 0.3333 & 0.3333 & 1.33 & & 0.66 & $67 \quad 0.6667$ & 1.6667 & \begin{tabular}{l|l}
7 & 0.2857
\end{tabular} & 0.2857 & 1.2857 \\
\hline $\mathrm{C} 2$ & 2.0000 & 3.0000 & 4.0000 & $1.0000 \quad 1$ & 1.0000 & 1.00 & & 1.00 & 2.0000 & 3.0000 & 0.8571 & 0.8571 & 1.8571 \\
\hline $\mathrm{C} 3$ & 0.5000 & 1.5000 & 2.5000 & 0.5000 & 0.5000 & 1.50 & & 1.00 & 1.0000 & 1.0000 & 0.4286 & 0.4286 & 1.4286 \\
\hline $\mathrm{C} 4$ & 2.5000 & 3.5000 & 4.5000 & 0.1667 & 1.1667 & 2.16 & & 1.33 & 2.3333 & 3.3333 & 1.0000 & 1.0000 & 1.0000 \\
\hline C5 & 0.5000 & 0.5000 & 1.5000 & 0.1667 & 0.1667 & 1.16 & & 0.33 & $33 \quad 0.3333$ & 1.3333 & 0.1429 & 0.1429 & 1.1429 \\
\hline C6 & 1.0000 & 2.0000 & 3.0000 & 0.6667 & 0.6667 & 1.66 & & 0.33 & 1.3333 & 2.3333 & 0.5714 & 0.5714 & 1.5714 \\
\hline $\mathrm{C} 7$ & 3.5000 & 4.5000 & 5.5000 & $0.5000 \quad 1$ & 1.5000 & 2.50 & & 2.00 & 3.0000 & 4.0000 & 0.2857 & 1.2857 & 2.2857 \\
\hline & & $\mathrm{C} 5$ & & & C6 & & & & & $\mathrm{C} 7$ & & & \\
\hline & $\mathrm{L}$ & $\mathrm{m}$ & $\mathrm{u}$ & 1 & $\mathrm{~m}$ & & $\mathrm{u}$ & & 1 & $\mathrm{~m}$ & $\mathrm{u}$ & & \\
\hline $\mathrm{C} 1$ & 1.0000 & 2.0000 & 3.0000 & 0.5000 & 0.500 & & 1.50 & & 0.2222 & 0.2222 & 1.2222 & & \\
\hline $\mathrm{C} 2$ & 5.0000 & 6.0000 & 7.0000 & 0.5000 & 1.500 & & 2.50 & & 0.6667 & 0.6667 & 1.6667 & & \\
\hline $\mathrm{C} 3$ & 2.0000 & 3.0000 & 4.0000 & 0.7500 & 0.750 & & 1.75 & & 0.3333 & 0.3333 & 1.3333 & & \\
\hline $\mathrm{C} 4$ & 6.0000 & 7.0000 & 8.0000 & 0.7500 & 1.750 & & 2.75 & & 0.7778 & 0.7778 & 1.7778 & & \\
\hline $\mathrm{C} 5$ & 1.0000 & 1.0000 & 1.0000 & 0.2500 & 0.250 & & 1.25 & & 0.1111 & 0.1111 & 1.1111 & & \\
\hline C6 & 3.0000 & 4.0000 & 5.0000 & 1.0000 & 1.000 & & 1.00 & 00 & 0.4444 & 0.4444 & 1.4444 & & \\
\hline C7 & 9.0000 & 9.0000 & 9.0000 & 1.2500 & 2.250 & & 3.25 & & 1.0000 & 1.0000 & 1.0000 & & \\
\hline
\end{tabular}


3. Menghitung jumlah baris $\sum_{j=i}^{m} M_{g_{i}}^{j}=\left(\sum_{j=1}^{m} l_{j} ; \sum_{j=1}^{m} m_{j} ; \sum_{j=1}^{m} u_{j}\right)$

Tabel 7. Rumus Umum Perhitungan Jumlah Baris

\begin{tabular}{|c|c|c|c|}
\hline \multicolumn{4}{|c|}{ Jumlah Baris } \\
\hline & 1 & $\mathrm{~m}$ & $\mathrm{U}$ \\
\hline $\mathrm{C} 1 \mathrm{~T}$ & $1 \mathrm{C} 1+. .+\mathrm{lC} 7$ & $\mathrm{mC} 1+. .+\mathrm{mC} 7$ & $\mathrm{uC} 1+. .+\mathrm{uC} 7$ \\
\hline $\mathrm{C} 2 \mathrm{~T}$ & $1 \mathrm{C} 1+. .+\mathrm{lC} 7$ & $\mathrm{mC} 1+. .+\mathrm{mC} 7$ & $\mathrm{uC} 1+. .+\mathrm{uC} 7$ \\
\hline $\mathrm{C} 3 \mathrm{~T}$ & $1 \mathrm{C} 1+. .+\mathrm{lC} 7$ & $\mathrm{mC} 1+. .+\mathrm{mC} 7$ & $\mathrm{uC} 1+. .+\mathrm{uC} 7$ \\
\hline $\mathrm{C} 4 \mathrm{~T}$ & $1 \mathrm{C} 1+. .+\mathrm{lC} 7$ & $\mathrm{mC} 1+. .+\mathrm{mC} 7$ & $\mathrm{uC} 1+. .+\mathrm{uC} 7$ \\
\hline $\mathrm{C} 5 \mathrm{~T}$ & $1 \mathrm{C} 1+. .+\mathrm{lC} 7$ & $\mathrm{mC} 1+. .+\mathrm{mC} 7$ & $\mathrm{uC} 1+. .+\mathrm{uC} 7$ \\
\hline $\mathrm{C} 6 \mathrm{~T}$ & $1 \mathrm{C} 1+. .+\mathrm{lC} 7$ & $\mathrm{mC} 1+. .+\mathrm{mC} 7$ & $\mathrm{uC} 1+. .+\mathrm{uC} 7$ \\
\hline $\mathrm{C} 7 \mathrm{~T}$ & $1 \mathrm{C} 1+. .+\mathrm{lC} 7$ & $\mathrm{mC} 1+. .+\mathrm{mC} 7$ & $\mathrm{uC} 1+. .+\mathrm{uC} 7$ \\
\hline
\end{tabular}

Tabel 8. Hasil Perhitungan Jumlah Baris

\begin{tabular}{|l|c|c|c|}
\hline \multicolumn{4}{|c|}{ Jumlah Baris (Sigma TFN) } \\
\hline & 1 & $\mathrm{~m}$ & $\mathrm{U}$ \\
\hline C1T & 4.0079 & 5.0079 & 11.0079 \\
\hline C2T & 11.0238 & 15.0238 & 21.0238 \\
\hline C3T & 5.5119 & 7.5119 & 13.5119 \\
\hline C4T & 12.5278 & 17.5278 & 23.5278 \\
\hline C5T & 2.5040 & 2.5040 & 8.5040 \\
\hline C6T & 7.0159 & 10.0159 & 16.0159 \\
\hline C7T & 17.5357 & 22.5357 & 27.5357 \\
\hline
\end{tabular}

4. Menghitung jumlah kolom $\left[\sum_{i=1}^{n} \sum_{j=1}^{m} M_{g_{i}}^{j}\right]=\left(\sum_{j=1}^{m} l_{j} ; \sum_{j=1}^{m} m_{j} ; \sum_{j=1}^{m} u_{j}\right)$

Tabel 9. Hasil Perhitungan Jumlah Kolom

\begin{tabular}{|c|c|c|c|}
\hline \multicolumn{4}{|c|}{ Jumlah Kolom } \\
\hline & 1 & $\mathrm{~m}$ & $\mathrm{U}$ \\
\hline JK & 60.1270 & 80.1270 & 121.1270 \\
\hline
\end{tabular}

5. Menghitung invers jumlah $\operatorname{kolom}\left[\sum_{i=1}^{n} \sum_{j=1}^{m} M_{g_{i}}^{j}\right]^{-1}=\left(\frac{1}{\sum_{i=1}^{n} u_{i}} ; \frac{1}{\sum_{i=1}^{n} m_{i}} ; \frac{1}{\sum_{i=1}^{n} l_{i}}\right)$ 
Tabel 10. Rumus Umum Perhitungan Invers Jumlah Kolom

\begin{tabular}{|c|c|c|c|}
\hline \multicolumn{4}{|c|}{ Invers Jumlah Kolom } \\
\hline & 1 & $\mathrm{~m}$ & $\mathrm{u}$ \\
\hline $\mathrm{iJK}$ & $1 / \mathrm{uJK}$ & $1 / \mathrm{mJK}$ & $1 / 1 \mathrm{JK}$ \\
\hline
\end{tabular}

Tabel 11. Hasil Perhitungan Invers Jumlah Kolom

\begin{tabular}{|c|c|c|c|}
\hline \multicolumn{4}{|c|}{ Invers Jumlah Kolom } \\
\hline & 1 & $\mathrm{~m}$ & $\mathrm{u}$ \\
\hline iJK & 0.0083 & 0.0125 & 0.0166 \\
\hline
\end{tabular}

6. Menghitung nilai Fuzzy Synthetic Extent $S_{i}=\sum_{j=i}^{m} M_{g_{i}}^{j} \otimes\left[\sum_{i=1}^{n} \sum_{j=1}^{m} M_{g_{i}}^{j}\right]^{-1}$

Tabel 12. Rumus Umum Perhitungan Fuzzy Synthetic Extent

\begin{tabular}{|c|c|c|c|}
\hline \multicolumn{4}{|c|}{ Fuzzy Synthetic Extent } \\
\hline & 1 & $\mathrm{~m}$ & $\mathrm{u}$ \\
\hline S1 & 1C1T x liJK & mC1T x miJK & uC1T x uiJK \\
\hline $\mathrm{S} 2$ & 1C2T x liJK & mC2T x miJK & uC2T x uiJK \\
\hline S3 & 1C3T x liJK & mC3T x miJK & uC3T x uiJK \\
\hline S4 & 1C4T x liJK & mC4T x miJK & uC4T x uiJK \\
\hline S5 & 1C5T x liJK & mC5T x miJK & uC5T x uiJK \\
\hline S6 & 1C6T x liJK & mC6T x miJK & uC6T x uiJK \\
\hline S7 & 1C7T x liJK & mC7T x miJK & uC7T x uiJK \\
\hline
\end{tabular}

Tabel 13. Hasil Perhitungan Fuzzy Synthetic Extent

\begin{tabular}{|c|c|c|c|}
\hline \multicolumn{4}{|c|}{ Fuzzy Synthetic Extent } \\
\hline & 1 & $\mathrm{~m}$ & $\mathrm{u}$ \\
\hline S1 & 0.0331 & 0.0625 & 0.1831 \\
\hline S2 & 0.0910 & 0.1875 & 0.3497 \\
\hline S3 & 0.0455 & 0.0938 & 0.2247 \\
\hline S4 & 0.1034 & 0.2188 & 0.3913 \\
\hline S5 & 0.0207 & 0.0313 & 0.1414 \\
\hline S6 & 0.0579 & 0.1250 & 0.2664 \\
\hline S7 & 0.1448 & 0.2813 & 0.4580 \\
\hline
\end{tabular}


7. Menghitung perbandingan Fuzzy Synthetic Extent

$$
V\left(S_{i} \geq S_{k}\right)=\left\{\begin{array}{lr}
1 ; & m_{S_{i}} \geq m_{S_{k}} \\
0 ; & l_{S_{k}} \geq u_{S_{i}} \\
& \left(l_{S_{k}}-u_{S_{i}}\right) \\
\left(\left(m_{S_{i}}-u_{S_{i}}\right)-\left(m_{S_{k}}-l_{S_{k}}\right)\right) & \text { lainnya }
\end{array}\right.
$$

Tabel 14. Hasil Perhitungan Fuzzy Synthetic Extent

\begin{tabular}{|c|c|c|c|c|c|c|c|}
\hline \multicolumn{7}{|c|}{ Perbandingan Fuzzy Synthetic Extent } \\
\hline & S1 $>=$ & S2 $>=$ & S3 $>=$ & S4 $>=$ & S5 $>=$ & S6 $>=$ & S7 $>=$ \\
\hline S1 & 1.0000 & 1.0000 & 1.0000 & 1.0000 & 0.7761 & 1.0000 & 1.0000 \\
\hline S2 & 0.4241 & 1.0000 & 0.5878 & 1.0000 & 0.2440 & 0.7372 & 1.0000 \\
\hline S3 & 0.8149 & 1.0000 & 1.0000 & 1.0000 & 0.6055 & 1.0000 & 1.0000 \\
\hline S4 & 0.3376 & 0.8874 & 0.4925 & 1.0000 & 0.1685 & 0.6348 & 1.0000 \\
\hline S5 & 1.0000 & 1.0000 & 1.0000 & 1.0000 & 1.0000 & 1.0000 & 1.0000 \\
\hline S6 & 0.6669 & 1.0000 & 0.8422 & 1.0000 & 0.4711 & 1.0000 & 1.0000 \\
\hline S7 & 0.1490 & 0.6861 & 0.2989 & 0.7978 & 0.0000 & 0.4376 & 1.0000 \\
\hline
\end{tabular}

8. Menghitung nilai bobot $d_{i}^{\prime}=\min \left(V\left(S_{i} \geq S_{k}\right)\right)$

Tabel 15. Rumus Umum Perhitungan Nilai Bobot

\begin{tabular}{|c|c|c|c|c|c|c|c|c|}
\hline \multicolumn{9}{|c|}{ Nilai Bobot } \\
\hline Bobot & S1 & $\mathrm{S} 2$ & S3 & S4 & S5 & S6 & S7 & $\begin{array}{c}\text { Total } \\
\left(\operatorname{Td}^{\prime}(\mathrm{An})\right)\end{array}$ \\
\hline $\mathrm{d}^{\prime}(\mathrm{An})$ & $\begin{array}{c}\min \\
(\mathrm{S} 1>= \\
(\mathrm{S} 1, \ldots, \mathrm{S} 7))\end{array}$ & $\begin{array}{c}\min \\
(\mathrm{S} 2>= \\
(\mathrm{S} 1, . ., \mathrm{S} 7))\end{array}$ & $\begin{array}{c}\min \\
(\mathrm{S} 3>= \\
(\mathrm{S} 1, . ., \mathrm{S} 7))\end{array}$ & $\begin{array}{c}\min \\
(\mathrm{S} 4>= \\
(\mathrm{S} 1, \ldots, \mathrm{S} 7))\end{array}$ & $\begin{array}{c}\min \\
(\mathrm{S} 5>= \\
(\mathrm{S} 1, . ., \mathrm{S} 7))\end{array}$ & $\begin{array}{c}\min \\
(\mathrm{S} 6>= \\
(\mathrm{S} 1, . ., \mathrm{S} 7))\end{array}$ & $\begin{array}{c}\min \\
(\mathrm{S} 7>= \\
(\mathrm{S} 1, \ldots, \mathrm{S} 7))\end{array}$ & $\begin{array}{c}\mathrm{d}^{\prime}(\mathrm{A} 1) \\
+. .+ \\
\mathrm{d}^{\prime}(\mathrm{A} 7)\end{array}$ \\
\hline
\end{tabular}

Tabel 16. Hasil Perhitungan Nilai Bobot

\begin{tabular}{|c|c|c|c|c|c|c|c|c|}
\hline \multicolumn{10}{|c|}{ Nilai Bobot } \\
\hline Bobot & S1 & S2 & S3 & S4 & S5 & S6 & S7 & Total \\
\hline d'(An) & 0.1490 & 0.6861 & 0.2989 & 0.7978 & 0.0000 & 0.4376 & 1.0000 & 3.3694 \\
\hline
\end{tabular}

9. Normalisasi nilai bobot $\left(d_{i}=\frac{d^{\prime}{ }_{i}}{\sum_{i=1}^{n} d^{\prime}{ }_{i}}\right)$ 
Tabel 17. Rumus Umum Normalisasi Bobot

\begin{tabular}{|c|c|c|c|c|c|c|c|}
\hline \multicolumn{8}{|c|}{ Normalisasi Nilai Bobot } \\
\hline Bobot & S1 & S2 & S3 & S4 & S5 & S6 & S7 \\
\hline \multirow{2}{*}{$\mathrm{d}(\mathrm{An})$} & $\mathrm{d}^{\prime}(\mathrm{A} 1)$ & $\begin{array}{l}\text { d'(A2) } \\
\text { (A) }\end{array}$ & $\mathrm{d}^{\prime}(\mathrm{A} 3$ & 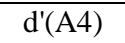 & d'(A5) & d'(A6) & $\mathrm{d}^{\prime}(\mathrm{A} 7)$ \\
\hline & /Td'(An) & $/ \mathrm{Td}^{\prime}(\mathrm{An})$ & )/Td'(An) & $/ \mathrm{Td}^{\prime}(\mathrm{An})$ & $/ \mathrm{Td}^{\prime}(\mathrm{An})$ & /Td'(an) & $/ \mathrm{Td}^{\prime}(\mathrm{an})$ \\
\hline
\end{tabular}

Tabel 18. Hasil Normalisasi Bobot

\begin{tabular}{|c|c|c|c|c|c|c|c|}
\hline \multicolumn{7}{|c|}{ Normalisasi Nilai Bobot } \\
\hline Bobot & S1 & S2 & S3 & S4 & S5 & S6 & S7 \\
\hline d(An) & 0.0442 & 0.2036 & 0.0887 & 0.2368 & 0.0000 & 0.1299 & 0.2968 \\
\hline
\end{tabular}

10. Menghitung bobot global

$$
\tilde{P}_{i}=\left(\widetilde{w}_{1} \otimes d\left(A_{1}\right) \oplus\left(\widetilde{w}_{2} \otimes d\left(A_{2}\right)\right) \oplus \cdots \oplus\left(\widetilde{w}_{j} \otimes d\left(A_{i}\right)\right)\right.
$$

dengan: $\quad \tilde{P}_{i}$ adalah bobot global dari notebook ke $i$,

$$
\begin{aligned}
& \widetilde{w}_{1} \text { adalah normalisasi skala dari kriteria } 1, \\
& \widetilde{w}_{2} \text { adalah normalisasi skala dari kriteria } 2 \text {, } \\
& \widetilde{w}_{j} \text { adalah normalisasi skala dari kriteria } j,
\end{aligned}
$$

Karenanya, rumus umum untuk menghitung bobot global dari kasus diatas adalah:

$$
\begin{gathered}
\tilde{P}_{1}=\left(\widetilde{w}_{1} \otimes d\left(A_{1}\right) \oplus\left(\widetilde{w}_{2} \otimes d\left(A_{2}\right)\right) \oplus \cdots \oplus\left(\widetilde{w}_{7} \otimes d\left(A_{7}\right)\right)\right. \\
\tilde{P}_{1}=\left(\widetilde{w}_{1} \otimes 0.0442\right) \oplus\left(\widetilde{w}_{2} \otimes 0.2036\right) \oplus\left(\widetilde{w}_{3} \otimes 0.0887\right) \\
\bigoplus\left(\widetilde{w}_{4} \otimes 0.2368\right) \oplus\left(\widetilde{w}_{5} \otimes 0\right) \oplus\left(\widetilde{w}_{6} \otimes 0.1299\right) \\
\left.\bigoplus\left(\widetilde{w}_{7} \otimes 0.296\right)\right)
\end{gathered}
$$

dan dihitung hingga semua notebook mendapatkan nilai prioritas global.

\section{KESIMPULAN DAN SARAN}

Dari hasil analisi terhadap masalah dan aplikasi yang telah dikembangkan, maka dapat disimpulkan yaitu Proses penggunaan aplikasi dilakukan oleh user. User melakukan input memilih skala prioritas dari setiap kriteria. Aplikasi akan melakukan perhitungan, kemudian output yang dihasilkan adalah 10 rekomendasi notebook dengan nilai bobot tertinggi. Adapun sarannya adalah Menambah kriteria lain seperti VGA, tipe RAM, berat notebook, ketebalan notebook, dan 
fitur-fitur tambahan lainnya agar kriteria yang diperhitungkan lebih lengkap sebagai pertimbangan bagi user.

\section{DAFTAR PUSTAKA}

Alias, M. A., Hashim, S. Z., dan Samsudin, S., Using Fuzzy Analytic Hierarchy Process for Southern Johor River Ranking, Int. J. Advance. Soft Comput. Appl., 1(1) (2009), 62-76.

Anton, H., Elementary Linear Algebra, John Wiley and Sons, 2000.

Febryansyah, A., Mengukur Kesuksesan Produk pada Tahap Desain: Sebuah Pendekatan Fuzzy-MCDM, Jurnal Teknik Industri, 8(2) (2006), 122-130.

Kusumadewi, S. dan Hartati, S., Neuro-Fuzzy Integrasi Sistem Fuzzy \& Jaringan Syaraf, Edisi Kedua, Graha Ilmu, Yogyakarta, 2010.

Safaat, N., Pemrograman Aplikasi Mobile Smartphone dan Tablet PC Berbasis Android, Penerbit Informatika, Bandung, 2010. 